\title{
Young Children's Social Information Processing: Family Antecedents and Behavioral Correlates
}

\author{
Kevin C. Runions \\ Edith Cowan University
}

\author{
Daniel P. Keating \\ University of Michigan
}

\begin{abstract}
Little research has examined whether social information processing (SIP) measures from early childhood predict externalizing problems beyond the shared association with familial risk markers. In the present study, family antecedents and first-grade externalizing behaviors were studied in relation to preschool and 1st-grade SIP using data from the U.S. National Institute for Child Health and Human Development Study of Early Child Care $(N=1,364)$. A subgroup of low-risk children reported only benign attributions in preschool and had few externalizing problems in 1st grade according to both teacher and mother reports. After controlling for gender and cognitive functioning, the authors found that maternal education and authoritarian attitudes were key predictors of this "Pollyanna preschooler" status and of SIP in 1st grade. However, small effect sizes for SIP variables underscore the need for new approaches to measurement and for further research on moderators of the link between SIP and children's behavior.
\end{abstract}

Keywords: social information processing, behavior problems, psychosocial development, parenting

Beginning with Dodge (1980), a substantial body of research has demonstrated that children with behavior problems often show distinctly maladaptive social information processing (SIP). But answers to the central question of whether SIP plays a causal role in children's behavioral development remain elusive. Unraveling the etiology of aggression-related SIP is important as interventions to address behavior problems in young children increasingly target these processes. But most studies have not adopted a longitudinal design, and when they have, they have not incorporated the range of risk markers that are implicated in the etiology of behavior problems. These past limitations make it difficult to assess whether SIP patterns are more than incidental to the development of behavior problems. Furthermore, little is known about the stability of SIP variables over early childhood or about how individual differences in SIP arise in early childhood. In the present study, we examined whether early SIP measures predict later externalizing tendencies after accounting for antecedent risk markers, and we tested hypotheses about the role of these risk markers in predicting individual differences in children's SIP.

Kevin C. Runions, Child Health Promotion Research Center and School of Psychology, Edith Cowan University, Perth, Western Australia; Daniel P. Keating, Center for Human Growth and Development, University of Michigan.

The research in this article was based in part on analyses conducted as a part of a doctoral dissertation by Kevin C. Runions. Daniel P. Keating acknowledges the Canadian Institute for Advanced Research for its fellowship support. We thank Jennifer M. Jenkins, Katreena Scott, and Daniel Shaw for their comments on earlier versions of this article.

Correspondence concerning this article should be addressed to Kevin C. Runions, Child Health Promotion Research Centre, Pearson St., Churchlands, Perth, Western Australia 6018, Australia. E-mail: k.runions@ecu.edu.au

\section{Social Information Processing and Children's Social Maladjustment}

The Crick and Dodge (1994) SIP model identifies cognitive processes that operate in social interaction. Two components of this model have spawned much research: children's interpretation of others' intentions and their behavioral response planning. Most research about children's interpretation of social cues has examined whether children attribute hostile or benign intent to an antagonist involved in an ambiguous but unpleasant social mishap Many studies_-but not all (e.g., Crick \& Dodge, 1996; Downey \& Walker, 1989; Matthys, Cuperus, \& van Engeland, 1999)— have found that children with externalizing problems are likely to attribute hostile intent to the antagonist (e.g., Dodge, 1980; Dodge, Price, Bachorowski, \& Newman, 1990; Guerra \& Slaby, 1989). These hostile attributions of intent (HAI) are most strongly related to children's reactive aggression (Dodge \& Coie, 1987). Children with externalizing problems also appear to show more aggressive response planning (ARP) to perceived hostility (Dodge \& Coie, 1987; Dodge, Pettit, Bates, \& Valente, 1995). This seems to increase the likelihood of responding aggressively in real-life encounters (Hart, Ladd, \& Burleson, 1990) and may exacerbate children's behavior problems.

\section{The Early Development of Social Information Processing}

Although a wealth of research has examined the relationship between SIP and children's behavioral adjustment, there has been less emphasis on understanding SIP as a developmental phenomenon, and longitudinal research has been remarkably scarce. There is some-albeit limited-evidence of modest stability of SIP through early to middle childhood. Dodge et al. (2003) found a small but significant correlation $(r=.18)$ between first- and fourth-grade attributions scores. Another longitudinal study, with high-risk participants, reported that overall HAI mean scores and standard deviations were stable between Grades 4 and 5, but the 
strength of associations across waves of data collection was not reported (Zelli, Dodge, Lochman, Laird, \& Conduct Disorders Prevention Group, 1999). Furthermore, little longitudinal research has examined SIP in young children. Assessments of SIP over early childhood are particularly interesting to developmentalists in light of the dramatic changes in children's understanding of mental concepts like intentionality.

\section{Social Information Processing and Cognitive Functioning in the Preschool Years}

Crick and Dodge (1994) noted that developmental changes in children's understanding of the psychological bases for behavior influence SIP. Children's understanding of mental constructs such as intention, desire, and belief develop rapidly during the preschool years. Although preschoolers do not fully appreciate the complex relationship between intention, desire, and action (Astington, 2001; Baird \& Moses, 2001), children as young as 3 years of age appear to understand desire (Wellman \& Wooley, 1990) and can distinguish between intended and accidental action (Shultz, Wells, \& Sarda, 1980). These early developing capacities make it likely that children can distinguish between behaviors that are accidental and those that unfold as planned and desired.

By the preschool years, tendencies to ascribe more or less hostile intent to others for unpleasant social mishaps already covary with problem behavior. In a study of 59 preschool-age boys from a community sample, Feshbach (1989) found a significant relationship between HAI and teacher reports of aggressive behavior. Webster-Stratton and Lindsay (1999) found that a clinical group of preschool and early-school-age children reported significantly more HAI than did a control group. Furthermore, children's HAI scores were significantly correlated with a range of concurrent measures including peer interactions; interactions with mothers and fathers; and maternal, paternal, and teacher reports of conduct problems. These findings indicate that individual differences in SIP arise early in the development of children's understanding of mentalistic constructs.

Other studies, however, have raised questions about the construct validity of HAI measures amongst preschool-age children. Katsurada and Sugawara (1998) used a pretest vignette that $100 \%$ of adult raters had judged as intentionally malicious and found that $22 \%$ of a preschool sample attributed an accidental cause to the vignette. These children were significantly younger than the final analysis sample (54 vs. 58 months old) but were not significantly different in terms of socioeconomic status, mothers' age, ethnicity, or teacher-rated aggression. Although the researchers considered that these children might have had a "benign attributional bias" ( $\mathrm{p}$. 629 ), they concluded that, due to their younger age, the children were more likely unable to differentiate intentional and unintentional behaviors. These children were excluded from the main analyses on the basis of this screening result.

Pettit, Dodge, and Brown (1988) encountered a different problem in measuring HAI in preschoolers. In their study of 46 children from economically disadvantaged backgrounds, all of the participating children reported strongly hostile attributions. The authors proposed that the children might have failed to understand the questions and thereby conflated negative outcomes and hostile intentions.
In both Pettit et al. (1988) and Katsurada and Sugawara (1998), the researchers suggested that children were failing to understand either the questions or the notion of intention, thereby suggesting a conflation of children's general cognitive functioning and their SIP. In a study that examined HAI in 3.5-year-old children, Cassidy, Kirsh, Scolton, and Parke (1996) noted that very young children might experience a floor effect given the relative difficulty of reasoning about unobservable events. Also, studies that controlled for IQ reported smaller effect sizes for the association between HAI and aggression (Orobio de Castro, Veerman, Koops, Bosch, \& Monshouwer, 2002). It is possible that individual differences in SIP are artifacts of individual differences in cognitive functioning (Dishion, French, \& Patterson, 1995; Gomez \& Hazeldine, 1996). A closer examination of the relationship of general cognitive functioning to SIP is needed, especially for preschoolage children.

\section{Antecedent Risk Markers and Subsequent Externalizing Outcomes}

A primary goal of this study was to examine whether early childhood SIP accounted for variance in children's externalizing behavior beyond the effects of a range of common risk markers for those behaviors. These risk markers have been shown to predict both SIP and externalizing outcomes and include family context (i.e., income and maternal education) and proximal parent variables (i.e., maternal depression, authoritarian attitudes, and harsh parenting behaviors). Moreover, if SIP variables are part of the etiology of externalizing behaviors, we would expect these variables to mediate the common risk markers.

\section{Socioeconomic Circumstances and Social Information Processing}

Given that socioeconomic status (SES) is one of the most consistent predictors of childhood behavior problems (Bradley \& Corwyn, 2002), it is not surprising that children from less affluent backgrounds show more maladaptive SIP (Chen, Langer, Raphaelson, \& Matthews, 2004; Chen \& Matthews, 2001; Pettit et al., 1988; Schultz \& Shaw, 2003). To better understand the potential etiology of SIP and externalizing problems, we differentiated the human capital (e.g., education) and financial capital (e.g., income) components of SES. Maternal education is an important predictor of preschoolers' perspective-taking abilities (Pears \& Moses, 2003), academic and intellectual performance (Andersson, Sommerfelt, Sonnander, \& Ahlsten, 1996), and early language skills (Cutting \& Dunn, 1999), which suggests it may be particularly important to children's understanding and interpretation of intentions.

Family income may support different mechanisms that lead to maladaptive SIP. Pettit et al. (1988), for example, suggested that socioeconomic disadvantage might engender a familial climate of mistrust of "outsiders" (p. 118), thus leading to HAI in children. But there may also be indirect pathways. High levels of stress due to financial difficulties may strain the capacity of parents to interact with children in a positive manner (Wahler \& Dumas, 1989), resulting in negative and controlling parenting behaviors. Thus, the present study sought (a) to test the relative importance of distinct aspects of family SES (income and maternal education) in 
predicting children's SIP and (b) to examine whether aspects of parenting fit a mediation model with SES and SIP.

\section{Parenting and Social Information Processing}

Emotionally harsh parenting behaviors and authoritarian attitudes (e.g., Rubin, Hastings, Chen, Stewart, \& McNichol, 1998; Shaw, Owens, Giovannelli, \& Winslow, 2001), as well as maternal depression (Downey \& Coyne, 1990), are well-established risk markers of young children's behavior problems. Their status as causal factors in the etiology of these problems is increasingly accepted (Cowan \& Cowan, 2002; Rubin, Burgess, Dwyer, \& Hastings, 2003). Less well established is whether these risk factors might be involved in the etiology of children's SIP.

Parental attitudes toward the acceptability of aggression have been shown to be significant predictors of children's social problem solving but do not predict the aggressiveness of children's responses (Pettit et al., 1988). Measures of parent HAI are inconsistently related to children's HAI (Bickett, Milich, \& Brown, 1996; MacBrayer, Milich, \& Hundley, 2003). Instead, more general attitudes may be more robust influences on children's socialcognitive development (Costanzo \& Dix, 1983). Authoritarian attitudes may signal to children that they are incapable of appropriate behavior and are inherently bad (Darling \& Steinberg, 1993); generalization of these beliefs may lead children to consider other children to be fundamentally malicious.

Such authoritarian attitudes may be more prevalent in mothers with less education who have had less opportunity to acquire more child-centered parenting attitudes (e.g., through formal study or access to parenting information). Thus maternal attitudes may fit a mediation model in the prediction of children's HAI from maternal education.

Harsh and rejecting behaviors by parents have also been implicated in the development of maladaptive SIP. Extremes of such behaviors, such as physical abuse, predict children's SIP (Camras, Sachs-Alter, \& Ribordy, 1996; Dodge et al., 1995), but it is not clear whether less extreme cases are also at risk for maladaptive SIP. In a study of older, clinic-referred children, Gomez, Gomez, DeMello, and Tallent (2001) found that child-reported maternal controlling behaviors correlated with children's HAI. With kindergarten-age participants, Weiss, Dodge, Bates, and Pettit (1992) found a significant relationship between a retrospective maternal self-report of harsh discipline and HAI for 1 of 2 cohorts studied; ARP showed a small but consistent relationship with maternal harsh discipline for both cohorts. In Dodge et al. (1995), ARP — but not HAI - fit a partial mediation model from maternal retrospective self-reports of harsh discipline to externalizing outcomes. Harsh parenting behaviors may provide a model of aggression for children that children adopt as their most easily accessed response option. But the reliance of past research on reported parenting, whether by the parent or the child, limits our knowledge about the role of parenting in the development of SIP.

In the present study, we were able to observe harsh parenting by the mother, and we examined whether children's SIP mediated parental negative control and children's externalizing outcomes. As economic hardship can increase parental stress and impact on parenting quality (Wahler \& Dumas, 1989), we hypothesized that harsh parenting would mediate family income and children's aggressive response planning.
As noted, maternal depression is considered a good predictor of children's problems. However, the only previous study of antecedents of SIP to look at maternal depression found that once SES was controlled for, depression was not a significant predictor (Schultz \& Shaw, 2003). The present study provided another opportunity to look at the association of maternal depression to children's SIP, but in a community sample, while controlling for a broader range of potential confounds than was previously possible.

\section{The Current Study}

Using longitudinal data from the U.S. National Institute for Child Health and Human Development (NICHD) Study of Early Childcare (SECC), we examined three variables assessing children's social information processing. These included, for 4.5-yearold children, a measure of attribution of intent, and, during first grade, measures of HAI and ARP. We employed a range of child, socioeconomic, and familial variables that have been found to predict children's externalizing behavior problems.

Our aim was to assess three sets of research questions. First, we examined the relationships amongst our three SIP measures and with children's cognitive functioning. No previous study has reported on associations of SIP measures from preschool to early school age. In light of previous findings about preschoolers who showed uniform HAI response patterns, we also examined whether children who report only accidental or only hostile attributions differ from other children on concurrent cognitive functioning, subsequent SIP, or externalizing tendencies.

Second, we examined whether children's SIP predicted teacher and parent reports of externalizing tendencies once a range of risk markers were controlled for. Previous research has indicated that child cognitive functioning, maternal education, family income, maternal depression, harsh parenting, and authoritarian attitudes are all likely to be associated with children's externalizing tendencies. All of these, with the exception of depression, are also likely to covary with children's hostile SIP. The current study allowed a test of whether SIP predicts variance in externalizing scores beyond the risk markers it shares with externalizing outcomes. If this were the case, it would provide evidence for a potential causal role of SIP in the development of behavior problems.

Third, we conducted a close examination of the role of those risk markers in predicting individual differences in the SIP variables. These tests allowed preliminary assessment of hypotheses regarding which aspects of young children's risk contexts are most strongly associated with early differences in how children process social information. On the basis of our theoretical model, we expected maternal education, mediated by parenting attitudes, to be particularly important in predicting children's HAI. We expected family income, mediated by parental negative control, to be a key antecedent of ARP.

\section{Method}

\section{Data Source and Participants}

Participants for the present study were from the NICHD-SECC. The NICHD-SECC is a longitudinal dataset with a recruitment sample of 1,364 children and their families from 10 sites around the continental United States. (Recruitment details are available in 
NICHD Early Child Care Research Network, 1999b.) Data were collected through a combination of home visits, telephone interviews, and visits to a research laboratory.

Of the recruitment sample, complete-cases data were available for only 893 families, largely because of attrition over the course of the study. We conducted logistic regression analyses to examine the pattern of missingness, with subsequent analyses of mean differences on variables that had few missing values (Goodman \& Blum, 1996). Variables available from the first wave of NICHDSECC data collection, including child gender, maternal education, family income, maternal depression, authoritarian attitudes, and observed harsh parenting, were used as predictors of missing data in the final complete-cases dataset. The logistic regression was significant overall, $\chi^{2}(7, N=1,364)=35.12, p<.001$, indicating that attrition from the study was conditional on sociodemographic and maternal variables measured early in the study. With all predictors of missingness in the model, the only significant predictors were child gender $(B=0.33, S E=0.13, p<.01)$ and mother's harsh parenting behaviors $(B=0.10, S E=0.05, p<$ $.05)$. Univariate analyses indicated that families in the completecases sample differed from the other families in the recruitment sample. Mothers in the complete-cases sample were more educated than were mothers of children not included $(M=14.5$ years vs. 13.7 years $), t(1304)=5.54, p<.001$, and were more affluent according to income-to-needs ratios ( $M=3.62$ vs. 2.81$), t(684)=$ $6.81, p<.001)$. Families of male target children were less likely to be in the complete-cases sample (complete-cases sample: $49 \%$ boys; recruitment sample: $57 \%$ boys $), \chi^{2}(1, N=1,364)=7.84$, $p<.01$. Mothers of children from the complete-cases sample held less authoritarian parenting attitudes than did the other mothers, $t(1301)=-4.87, p<.001$, and were observed to be lower in negative control than the other mothers, $t(447)=-4.96, p<.001$. These mothers also had lower depression scores than did mothers who left the study $(M=9.26$ vs. 10.71$), t(648)=-3.32, p=$ .001 .

Of the complete-cases sample, $9.7 \%$ of the children were African American, $1.5 \%$ were Asian American, $0.2 \%$ were Indigenous American, $4 \%$ were Hispanic American, $80.4 \%$ were non-Hispanic European American, and $4.2 \%$ were classified as having other ethnicities.

\section{Overview of Data Collection Procedures}

The NICHD-SECC collected data in two phases. In the first phase, data collection occurred when the children were ages 1,6 , 15,24 , and 36 months. For the current analyses, the socioeconomic and maternal variables were limited to data from this collection period. The second phase of the NICHD-SECC followed the same families and consisted of three major data collections. Data collection in Phase II took place when the children were 54 months old, in kindergarten, and again in the spring of first grade. The first measure of children's attributions of intent and the assessment of cognitive functioning were collected when children were 54 months old. The second HAI measure and the ARP measure, as well as maternal and teacher reports of children's externalizing tendencies, were assessed in first grade. For $85.5 \%$ of the children, these assessments were conducted during the 1997-1998 school year, with the remainder conducted in the 1998-1999 school year. The mean age of participating children for the first-grade data collection was 6.98 years $(S D=0.29$; see NICHD Early Child Care Research Network, 2005, for further details on the first-grade data collection).

\section{Measures}

Socioeconomic context variables. Two SES measures were used. Maternal education (i.e., number of years of educational attainment) was assessed when the target child was 1 month old. Following Dearing, McCartney, and Taylor (2001), the incometo-needs ratio was used to index family income for the NICHDSECC sample. An income-to-needs ratio of one indicates the family is on the threshold of poverty. Higher scores indicate greater affluence, and scores of less than one indicate income levels below the poverty line. Multiple-year indicators of family income have been shown to be better predictors of children's outcomes than are single-year indicators (Blau, 1999). A composite income-to-needs variable was constructed for use in the current study to index the average overall income-to-needs status of each family for five measurement points from Month 1 to Month 36 . Internal consistency was excellent $(\alpha=.94)$.

Maternal functioning variables. Three measures of maternal functioning were used in the current study: maternal depression, maternal authoritarian attitudes, and observed maternal negative control. Self-reports of maternal depression were assessed using the My Feelings questionnaire from the Center of Epidemiological Studies Depression Scale (CES-D). At each age, a maternal depression score was calculated by summing the mother's responses to the 20 questions. A composite maternal depression score was calculated as the mean of the five scores. Maternal depression was stable between 1 and 36 months, showing good reliability $(\alpha=$ .84) amongst our complete-cases sample.

Maternal authoritarian attitude scores were derived from the Parental Modernity Scale of Child-Rearing and Education Beliefs, a 30-item Likert-style questionnaire administered to the mother when the child was 1 month old. This instrument has a two-factor structure, with a Traditional (i.e., authoritarian) subscale, reflecting beliefs that children should be deferential and obedient to adults (e.g., "Children must be carefully trained early in life or their natural impulses will make them unmanageable"), and a Progressive subscale, reflecting beliefs in child autonomy and selfdirection (e.g., "A child's ideas should be seriously considered in making family decisions"). Only the Traditional beliefs scores were used in the current analyses. This questionnaire was only administered when the child was 1 month old; equivalent measures between 6 and 36 months were not available.

Expressed maternal negative control was assessed from videotaped mother-child play interactions. Mothers were videotaped while engaged in a 15-min semistructured play session with their child at the 6-, 15-, 24-, and 36-month visits. (See NICHD Early Child Care Research Network, 1999a, for details of these procedures.) On the basis of our literature review, we focused on emotionally harsh, intrusive, and negative parenting. Thus, we used codes derived from the mother-child interactions that reflected these parenting behaviors and excluded parenting behaviors that have been less consistently associated with children's behavior problems in past research. From the 6-, 15-, and 24month assessments, codes for maternal negative regard for the child (frequency and intensity of negative affect directed at the 
child) and intrusiveness (the degree to which the mother seeks to control the play of the child) were used. From the 36-month assessment, maternal hostility (parental expression of angry affect or overt rejection or blame of the child) and respect for child's autonomy (parent behaves in a nonintrusive way and encourages independent thought and actions; reverse scored for the current analyses) were used. The composite was calculated as the mean of standardized scores for these eight variables. Cronbach's alpha for the composite was .75 .

Child cognitive functioning. At the 54-month visit, children were administered the Woodcock-Johnson Psychoeducational Battery-Revised (W-J). The W-J provides a broad assessment of cognitive functioning, including short-term memory, auditory processing, verbal comprehension, symbolic learning, and problem analysis. It has good internal consistency (split-half reliability for individual tests range from .70 to .94) and adequate test-retest reliability (ranging from .63 to .78 for individual tests). Cronbach's alpha was .80 across the five tests.

Children's HAI-preschool. Following Feshbach (1989) and Webster-Stratton and Lindsay (1999), vignettes were read to children to assess HAI during the 54-month laboratory visit. Children were presented with four gender-tailored hypothetical scenarios in which a bad thing happened to the child due to the actions of another child. The four scenarios were (a) being hit in the back by a ball while playing catch, (b) having a favorite toy taken (while the child was not watching) by another child, (c) having juice spilled on the child, and (d) tripping over another child's leg while playing. Children were asked whether they thought the action was intentional or accidental (e.g., "Did Sarah steal your doll or did Sarah find your doll and not know it was your doll?"). Three of the four stories distinguished the forced choice through the phrases "want to" and "by accident."

Internal consistency was marginal, with a Cronbach's alpha of .65. Item 2 (the stolen toy) was the least reliable item, with a corrected item total correlation of .27. This may be due to the difference in wording (i.e., absence of "want to" and "by accident" in the question). However, with this item removed, the alpha improved only marginally to .67. All four items were retained for final analyses.

Children's HAI-Grade 1. Children were presented with eight gender-tailored scenarios, each accompanied by a stick-figure drawing. These were adapted from the Fast Track project (Dodge, Pettit, McClaskey, \& Brown, 1986). Four of the scenarios involved physical transgressions; the other four scenarios involved overt social rejection. Children were asked an open-ended question about why the other child behaved as he or she did. Cronbach's alpha for this measure was .65 .

Children's ARP. During the Grade 1 SIP assessment, children were asked what they would do in each of the eight scenarios. Children's open-ended responses to each scenario were coded by the NICHD-SECC team on an ordinal 5-point scale. Originally, two response categories were used by the NICHD-SECC to represent ARP. Level 5 responses indicated direct retaliation, either physically or verbally. Level 4 responses included seeking an adult to punish the other child, threatening to do so, or otherwise threatening retaliation to the other child. The inclusion of child nominations to seek an adult to punish the child-arguably a socially competent strategy - and nominations to threaten retaliation within the same category gave us reservations about the validity of Level 4 responses as an index of ARP. For the current study, we used the frequency of direct retaliation nominations as the indicator of ARP.

Child Variables-Externalizing Tendencies. When children were in first grade, mothers completed the Child Behavior Checklist (CBCL; Achenbach \& Edelbrock, 1983). The CBCL is a widely used, normed, and validated assessment instrument covering a broad range of children's behavioral, emotional, and adjustment problems. The externalizing scale is a "broadband" scale, comprised of the delinquent behavior and aggressive behavior scales. Internal consistency was very good for this scale $(\alpha=.89)$.

During children's first grade, teacher reports of children's externalizing tendencies were also collected using the Teacher Report Form of the Child Behavior Profile (Achenbach \& Edelbrock, 1986).

\section{Results}

\section{Missing Values and Multiple Imputation}

The high rate of missing data prompted us to consider strategies to correct for potential bias that may have resulted from the selective attrition over the course of the study. The analyses of missingness reported earlier suggested that the data were not missing completely at random (MCAR; Rubin, 1976) but instead were missing on the basis in part of variables measured in this study (i.e., missing at random; MCAR; Rubin, 1976). This led us to adopt a multiple imputation strategy (Schafer \& Olsen, 1998).

We imputed our missing values using WinMICE 0.1 (Jacobusse, 2005). WinMICE imputations are based on a multivariate distribution, such that information from all other variables in the imputation model is used in imputing individual missing values (van Buuren \& Oudshoorn, 2000). For all continuous variables, a predictive mean matching algorithm was used; for dichotomous variables (e.g., HAI and ARP items), a logistic regression model was specified. Besides variables used in the current analyses, we included CBCL reports from 24 and 36 months, and Teacher Report Forms from kindergarten, which were available from earlier data collections. To improve imputation of missing values (Collins, Schafer, \& Kam, 2001), we added demographic variables from the first data collection that were not included in our conceptual model (i.e., maternal age, child's birth order, partner's education, and father residence with mother).

Ten complete data files were imputed, which resulted in reasonably low fractions of missing information and adequate degrees of freedom for significance testing of scalar estimands (von Hippel, 2005). The fraction of missing information is a parameter related to the estimation of the standard error for the imputation. As the fraction decreases, the estimate approximates the standard error that would be achieved based on an infinite number of imputations (von Hippel, 2005). Von Hippel has noted that with 10 imputed datasets and a missing value fraction of 0.4 , standard errors are only $2 \%$ larger than for the ideal case (i.e., infinite imputation). For imputations with the greatest risk of large fractions of missing values (e.g., the Grade 1 SIP variables), our fractions were all below 0.5 . The fraction of missing information was also related to the degrees of freedom used to test the imputed value. Large fractions of missing information can lead to very small degrees of freedom. For the current analyses, 10 imputations 
resulted in no degrees of freedom lower than 30, a rule of thumb suggested by von Hippel (n.d.), which corresponds with Rubin's (1976) suggestions. We combined analyses in Schafer's (2000) NORM package using Rubin's (1976) rules for combining scalar estimands and standard errors. All analyses reported are based on these estimates and standard errors.

\section{Social Information Processing and Cognitive Functioning}

Inspection of distribution of the SIP variables indicated that the preschool HAI variable was negatively kurtotic (estimate = $-1.18, S E=0.13)$. Just under a quarter of the analysis sample (24.0\%) reported solely accidental attributions for all four vignettes, $19.4 \%$ reported one hostile attribution, $23.2 \%$ reported two, $22.3 \%$ reported three, and $11.0 \%$ reported exclusively HAI to all four vignettes $(M=1.77, S D=1.33)$. The Grade $1 \mathrm{HAI}$ measure was normally distributed $(M=4.76, S D=2.03)$. The ARP variable $(M=0.72, S D=1.55)$ was both highly positively skewed (estimate $=2.74, S E=0.10$ ) and highly kurtotic (estimate $=7.47, S E=0.52$ ).

Given these distribution problems, analyses of association were conducted using Spearman's nonparametric procedure and all correlation coefficients reported are Spearman's rho. The three SIP variables showed small but significant intercorrelations. The rho for the preschool and school-age HAI measures was $.13(p<$ $.001)$, and the rho for preschool HAI and school-age ARP was .10 $(p<.01)$. Between the two school-age measures, rho was .20 $(p<.001)$. Associations between the SIP variables and children's cognitive functioning were also small but significant (preschool HAI $\rho \iota=-.13$; Grade 1 HAI $\rho \iota=-.21$; ARP $\rho \iota=-.12$; all $p s<.001)$.

To examine whether preschool-age children who attributed only benign or only hostile intent to the scenarios differed from other children, we conducted a one-way analysis of variance (ANOVA) with the five levels of the preschool HAI measure as our independent variable and concurrent cognitive functioning as the dependent variable. This indicated a significant effect of HAI level on cognitive functioning, $F(4,1359)=10.69, p<.001$. Dunnett $\mathrm{C}$ post hoc analyses indicated that the children who reported only accidental attributions scored significantly higher on the W-J $(M=$ 101.49) than did children who reported between one and four hostile attributions ( $M=96.71,96.32,97.35,97.05$, respectively). No other significant differences were observed.

To further examine extreme responses on the preschool HAI variable, similar ANOVAs were conducted for the Grade 1 SIP measures. The ANOVA for ARP was significant, $F(4,1359)=$ $5.45, p<.001$. Children who reported only accidental attributions of intent reported on average 0.41 aggressive response plans, which was significantly lower than for children scoring between two and four hostile attributions (marginal $M=0.81, p<.01$; $0.92, p<.001 ; 0.79, p<.05$, respectively). Dunnett $\mathrm{C}$ analyses indicated that the difference between children reporting only accidental attributions and those reporting one hostile attribution was significant only at the trend level (marginal $M=0.69$; estimate = $-0.28, S E=0.15, p<.10)$. The ANOVA with first-grade HAI as the dependent variable was also significant, $F(4,1359)=6.84$, $p<.001$. Dunnett $\mathrm{C}$ analyses indicated that the only significant differences were between children who reported exclusively nonhostile attributions of intent (first-grade HAI marginal $M=4.30$ ) and the rest of the children. No significant differences between children scoring between one and four HAI in preschool (one HAI $M=4.77$, two HAI $M=4.82$, three HAI $M=4.99$, four HAI $M=$ 5.13) were observed.

Thus, on the other measures of child cognitive and socialcognitive functioning, preschool-age children who reported only benign attributions were consistently different from children who reported any number of hostile attributions. In light of this consistent pattern, and given the distributional problems with the preschool variable, subsequent analyses were conducted using a dichotomized preschool HAI variable, with one group reporting only nonhostile attributions of intent and the other reporting any HAI.

\section{Social Information Processing and Externalizing Tendencies}

Our second research question addressed the role of SIP in the prediction of externalizing scores beyond their covariance with antecedent risk markers. The distributions of both the maternal and teacher reports of children's externalizing behaviors were significantly skewed (estimate $=1.04, S E=0.07$; estimate $=1.72, S E=$ 0.71, respectively). Logarithmic and square root transformations were calculated for both variables, and the transformation that resulted in the greater reduction in skew was retained. Logarithmic transformation was more effective in reducing skew for the teacher report (estimate $=0.13, S E=0.67$ ), and square root transformation was more effective for the maternal reports (estimate $=0.15$, $S E=0.92)$.

Our analytic strategy for model testing was identical for maternal and teacher reports of externalizing tendencies during first grade (see Table 1). At Step 1, we entered the child and family predictors, then at Step 2, the three social information processing variables. Entry of the Step 1 predictors accounted for $12.24 \%$ $(p<.001)$ of the variance in maternal reports and $12.26 \%(p<$ $.001)$ of the variance in teacher reports. Boys were seen by both mothers $(B=-0.175, S E=0.060, p<.01)$ and teachers $(B=$ $-0.196, S E=0.031, p<.001)$ as having greater externalizing tendencies than were girls. Children with higher cognitive functioning scores were seen as less disruptive by teachers only $(B=$ $-0.004, S E=0.001, p<.01)$. Mothers who self-reported more depressive symptoms reported more externalizing behaviors in their children $(B=0.040, S E=0.005, p<.001)$. It was possible that shared source variance might have inflated this relationship, so it was interesting to observe that maternal depression was not a significant predictor of teacher reports of children's externalizing behaviors $(B=0.003, S E=0.002, n s)$. The converse pattern was observed for maternal harsh control, which was a significant predictor of teacher reports $(B=0.036, S E=0.012, p<.01)$ but not of maternal reports. Maternal attitudes, education, and family income were nonsignificant in both models.

Entry of the SIP variables at Step 2 accounted for additional variance in both teacher reports $(1.76 \%$ of the variance; $p<.001)$ and maternal reports $(0.72 \%$ of the variance; $p<.05)$. In both cases, the preschool HAI showed the strongest relationship with externalizing outcomes (teacher report: $B=0.097, S E=0.033$, $p<.01$; maternal report: $B=0.200, S E=0.720, p<.001$ ). For teacher reports only, the first-grade HAI measure also contributed significantly to model fit $(B=0.020, S E=0.008, p<.05)$. ARP 
Table 1

Hierarchical Multiple Regression Analyses Predicting Maternal and Teacher Reports of Children's Externalizing Tendencies in First Grade $(N=1,364)$

\begin{tabular}{|c|c|c|c|c|}
\hline \multirow[b]{2}{*}{ Variable } & \multicolumn{2}{|c|}{ Maternal report } & \multicolumn{2}{|c|}{ Teacher report } \\
\hline & $B$ & $S E$ & $B$ & $S E$ \\
\hline \multicolumn{5}{|l|}{ Step 1} \\
\hline Gender & -0.175 & $0.064^{* *}$ & -0.196 & $0.031^{* * * *}$ \\
\hline $\begin{array}{l}\text { Cognitive } \\
\text { functioning }\end{array}$ & -0.001 & 0.003 & -0.004 & $0.001^{* * *}$ \\
\hline Maternal education & -0.020 & 0.017 & -0.007 & 0.008 \\
\hline Family income & -0.017 & 0.015 & 0.001 & 0.006 \\
\hline Authoritarian attitude & 0.004 & 0.002 & 0.002 & 0.001 \\
\hline Negative control & 0.020 & 0.025 & 0.036 & $0.012^{* * *}$ \\
\hline Maternal depression & 0.040 & $0.005^{* * *}$ & 0.003 & 0.002 \\
\hline \multicolumn{5}{|l|}{ Step 2} \\
\hline Gender & -0.160 & $0.065^{*}$ & -0.182 & $0.031^{* * *}$ \\
\hline $\begin{array}{l}\text { Cognitive } \\
\text { functioning }\end{array}$ & 0.001 & 0.004 & -0.003 & $0.001^{*}$ \\
\hline Maternal education & -0.018 & 0.018 & -0.005 & 0.008 \\
\hline Family income & -0.018 & 0.015 & 0.001 & 0.006 \\
\hline Authoritarian attitude & 0.003 & 0.002 & 0.001 & 0.001 \\
\hline Negative control & 0.019 & 0.024 & 0.033 & $0.011^{* * *}$ \\
\hline Maternal depression & 0.040 & $0.005^{* * * *}$ & 0.003 & 0.002 \\
\hline Preschool HAI & 0.200 & $0.072^{* * *}$ & 0.097 & $0.033^{* *}$ \\
\hline School age HAI & 0.010 & 0.016 & 0.020 & $0.008^{*}$ \\
\hline School age ARP & -0.008 & 0.087 & 0.044 & 0.036 \\
\hline
\end{tabular}

Note. Child Behavior Checklist: $R^{2}=.122$ for Step $1 ; \Delta R^{2}=.007$ for Step 2. Teacher Report Form: $R^{2}=.123$ for Step $1 ; \Delta R^{2}=.018$ for Step 2. Based on analyses of data multiply imputed from 893 complete cases. $\mathrm{HAI}=$ hostile attributions of intent; $\mathrm{ARP}=$ aggressive response planning. ${ }^{*} p \leq .05 .{ }^{* * *} p \leq .01 .{ }^{* * * *} p \leq .001$.

was nonsignificant in both models. There was no evidence of mediation of family antecedents by SIP in either maternal or teacher reports of children's externalizing tendencies.

\section{Antecedents of Social Information Processing}

Because the hostile attribution of intent measure from the preschool assessment and, to a lesser extent, the first-grade HAI assessment were significant predictors of children's externalizing scores, we conducted subsequent analyses to assess the developmental antecedents of these social information processing variables. To assess the similarity of relations with antecedent risk markers, we also examined the ARP variable, despite it not being a significant predictor.

Due to extreme kurtosis, initial analyses of the preschool HAI variable indicated violations of the assumptions of both OLS and ordinal logistic regression. We adopted a logistic regression analytic strategy based on a dichotomized preschool HAI variable. In the next analyses, we examined the role of risk markers as predictors of membership in an only-accidental group versus an any-hostile-attributions group. To test our mediation hypotheses, we conducted hierarchical analyses. At Step 1, we entered the two child predictors (gender and cognitive functioning) along with two SES risk markers (family income and maternal education). At Step 2 , we entered the three maternal risk markers (authoritarian attitudes, depression, and negative control).
As shown in Table 2, child gender and cognitive functioning were both significant predictors of preschool HAI $(B=-0.389$, $S E=0.142, p<.01 ; B=-0.027, S E=0.008, p<.001$, respectively). Children of better-educated mothers were less likely to report any HAI $(B=-0.103, S E=0.038, p<.01)$. The three maternal functioning variables were entered next and significantly improved model fit, $\chi^{2}(3, N=1,360)=8.43, p<.05$. Maternal authoritarian attitudes were a significant predictor $(B=0.012$, $S E=0.006, p<.05)$. The odds of reporting any HAI in preschool increased by $1.15 \%$ for each unit increase in maternal authoritarian attitudes $(S D=15.21)$. For the final model, the odds of reporting some HAI were $32.2 \%$ higher for boys than for girls, and the odds of reporting some HAI decreased by $2.1 \%$ for each unit increase in W-J composite scores (W-J $S D=11.72)$.

Entry of the maternal functioning variables corresponded with a drop to nonsignificance of the effect of maternal education on preschool HAI. This provided initial support to the hypothesis that maternal education and authoritarian attitudes fit a mediation model in predicting children's hostile attributions. A formal test of mediation was conducted using the Aroian cross-products test, which is a variant of the Sobel test (MacKinnon \& Dwyer, 1993; Preacher \& Leonardelli, 2001). The logistic regression of the HAI measure on maternal education was significant $(B=-0.149$, $S E=0.030, p<.001)$. The logistic regression with maternal authoritarian attitudes as the predictor of HAI was also significant $(B=0.026, S E=0.004, p<.001)$. Maternal attitudes were regressed on maternal education scores, which was also significant $(B=-3.34, S E=0.14, p<.001)$. The beta estimates and standard errors from these latter regressions were used in conducting the Aroian test, which was significant (Aroian test statistic $=$ $-4.89, p<.001$ ), indicating that maternal education, authoritarian attitudes, and children's HAI fit a mediation model.

Next, hierarchical multiple regression analyses were conducted for school-age HAI, and logistic regressions were conducted for school-age ARP (see Table 3). Preschool HAI was entered at the first step along with the other child variables and the family risk markers, which together accounted for $5.71 \%$ of the variance in the

Table 2

Hierarchical Logistic Regression Analyses Predicting Preschool Attribution of Intent Group from Child and Family Characteristics $(N=1,364)$

\begin{tabular}{lrcc}
\hline \multicolumn{1}{c}{ Variable } & $B$ & $S E$ & $t$ ratio \\
\hline Step 1 & & & \\
$\quad$ Child gender & -0.389 & 0.142 & $-2.75^{* * *}$ \\
Child cognitive functioning & -0.027 & 0.008 & $-3.46^{* * *}$ \\
$\quad$ Maternal education & -0.103 & 0.038 & $-2.73^{* *}$ \\
$\quad$ Family income & 0.015 & 0.032 & 0.47 \\
Step 2 & & & \\
$\quad$ Gender & 0.389 & 0.143 & $-2.73^{* * *}$ \\
Cognitive functioning & -0.021 & 0.008 & $-2.59^{*}$ \\
Maternal education & -0.064 & 0.040 & -1.60 \\
Family income & 0.028 & 0.032 & 0.88 \\
Authoritarian attitude & 0.012 & 0.006 & $1.98^{*}$ \\
Negative control & 0.054 & 0.006 & 0.87 \\
Maternal depression & 0.002 & 0.012 & 0.19 \\
\hline
\end{tabular}

Note. $\chi^{2}=61.77$ for Step $1(p<.001) ; \Delta \chi^{2}=8.43(p<.05)$. Based on analyses of data multiply imputed from 893 complete cases.

${ }^{*} p \leq .05 .{ }^{* *} p \leq .01 .{ }^{* * *} p \leq .001$. 
Table 3

Hierarchical Multiple Regression Analyses Predicting Grade 1 Hostile Attributions of Intent (HAI) and Hierarchical Logistic Regression Analyses Predicting Grade 1 Aggressive Response Planning (ARP; $N=1,364$ )

\begin{tabular}{|c|c|c|c|c|c|c|}
\hline \multirow[b]{2}{*}{ Variable } & \multicolumn{3}{|c|}{ HAI } & \multicolumn{3}{|c|}{ ARP } \\
\hline & $B$ & $S E$ & $t$ ratio & $B$ & $S E$ & $t$ ratio \\
\hline \multicolumn{7}{|l|}{ Step 1} \\
\hline Gender & -0.210 & 0.116 & $-1.81^{+}$ & -0.308 & 0.146 & $-2.11^{*}$ \\
\hline Cognitive functioning & -0.030 & 0.006 & $-4.93^{* * *}$ & -0.005 & 0.007 & -0.76 \\
\hline Preschool HAI & 0.420 & 0.149 & $2.82^{* *}$ & 0.440 & 0.181 & $2.43^{*}$ \\
\hline Maternal education & -0.003 & 0.030 & -0.10 & -0.159 & 0.043 & $-3.67^{* * * *}$ \\
\hline Family income & -0.025 & 0.025 & -0.98 & 0.044 & 0.038 & 1.17 \\
\hline \multicolumn{7}{|l|}{ Step 2} \\
\hline Gender & -0.223 & 0.116 & -1.92 & -0.310 & 0.150 & $-2.07^{*}$ \\
\hline Cognitive functioning & -0.024 & 0.006 & $-3.68^{* * * *}$ & 0.003 & 0.008 & 0.45 \\
\hline Preschool HAI & 0.381 & 0.147 & $2.60^{*}$ & 0.402 & 0.183 & $2.20 *$ \\
\hline Maternal education & 0.046 & 0.033 & 1.39 & -0.101 & 0.046 & $-2.20^{*}$ \\
\hline Family income & 0.005 & 0.027 & -0.17 & 0.072 & 0.038 & $1.91^{+}$ \\
\hline Authoritarian attitudes & 0.017 & 0.005 & $3.34^{* * * *}$ & 0.016 & 0.006 & $2.60^{* *}$ \\
\hline Negative control & 0.023 & 0.045 & 0.52 & 0.097 & 0.063 & 1.55 \\
\hline Maternal depression & 0.014 & 0.010 & 1.44 & 0.011 & 0.011 & 1.03 \\
\hline
\end{tabular}

Note. HAI: $R^{2}=.057$ for Step $1(p<.001) ; \Delta R^{2}=.015$ for Step $2(p<.05)$. ARP: $\chi^{2}=59.72$ for Step $1(p<.001) ; \Delta \chi^{2}=23.27$ for Step $2(p<$ $.001)$. Based on analyses of data multiply imputed from 893 complete cases.

${ }^{+} p \leq .1{ }^{*} p \leq .05 .{ }^{* * *} p \leq .01 .^{* * * *} p \leq .001$.

school-age HAI measure. This block also significantly improved model fit for the ARP measure, $\chi^{2}(5, N=1,358)=59.72, p<$ .001. Preschool HAI was a significant predictor of first-grade HAI $(B=0.420, S E=0.149, p<.01)$ and ARP $(B=0.440, S E=$ $0.181, p<.05)$. With preschool HAI controlled, gender was significant only at a trend level for HAI $(B=-0.210, S E=0.116$, $p<.10)$ but at conventional levels for ARP $(B=-0.308, S E=$ $0.146, p<.05)$. As expected, children with higher cognitive functioning scores attributed hostile intentions to fewer vignettes $(B=-0.030, S E=0.006, p<.001)$; cognitive functioning was not a significant predictor of ARP. Maternal education did not contribute to school-age HAI scores with preschool HAI in the model. But, contrary to our hypotheses, maternal education was a highly significant predictor of ARP $(B=-0.159, S E=0.043$, $p<.001)$, whereas family income was not.

At Step 2, the three proximal maternal predictors were entered, accounting for an additional $1.52 \%$ of the variance in Grade $1 \mathrm{HAI}$ scores. These three variables also improved model fit for the ARP variable, $\chi^{2}(3, N=1355)=23.28, p<.001$. As hypothesized, maternal authoritarian attitudes did predict greater HAI in first grade, even after controlling for children's cognitive performance and previous HAI tendencies $(B=0.017, S E=0.005, p<.001)$. However, there was no indication of the hypothesized mediation of maternal education by authoritarian attitudes. Again, contrary to our hypotheses, authoritarian attitudes, and not observed harsh parenting, predicted children's ARP $(B=0.016, S E=0.006, p<$ $.01)$.

The inclusion of maternal attitudes in the ARP regression model also coincided with a substantial drop in the size of the estimate of maternal education ( $B$ from -0.159 to -0.101$)$. As with the previous analysis of mediation for the preschool HAI variable, a formal test was conducted to assess this relationship. The logistic regression of ARP on maternal education was significant $(B=$ $-0.155, S E=0.034, p<.001)$, as was the regression of ARP on maternal attitudes $(B=0.027, S E=0.005, p<.001)$. The ordinary least squares regression of attitudes on maternal education was also significant $(B=-3.33, S E=0.137, p<.001)$. The Aroian test of cross-products indicated that these variables fit a mediation model (test statistic $=5.156, p<.001$ ). However, as noted earlier, ARP was not a significant predictor of children' externalizing scores, so the complete hypothesized mediation pathway was not supported.

\section{Discussion}

The current study was conducted to examine the importance of social information processing in early childhood to individual differences in externalizing tendencies after controlling for family and child risk markers. We were also able to assess the relationship between SIP assessments at two ages, as well as their relationship with individual differences in cognitive functioning. Finally, we examined the relationship between contextual antecedents and individual differences in SIP variables.

Our study makes several important contributions to our understanding of young children's SIP. We observed that almost a quarter of our participants attributed uniformly benign intentions to the unpleasant hypothetical vignettes presented to them. Compared with the other children, these "Pollyanna preschoolers" scored significantly higher on concurrent tests of cognitive functioning, reported fewer hostile attributions and aggressive response plans in first grade, and were seen by both mothers and teachers as having fewer externalizing tendencies in first grade. These findings lend support to the possibility that some preschool-age children demonstrate a benign attribution bias and are not misunderstanding the questions or the concept of intentional behavior (cf., Katsurada \& Sugawara, 1998). We found no evidence to support the previous observation (Pettit et al., 1988) that preschool-age children who show exclusively hostile attribution tendencies are 
disproportionately from disadvantaged backgrounds or are otherwise different from other children.

Unexpectedly, the preschool HAI variable was consistently a better predictor of problem behaviors than was the first-grade HAI assessment. Although we did not forward hypotheses on this point, we expected that concurrent SIP scores would be more strongly related to externalizing reports than would antecedent SIP scores. This unexpected relative strength of association, combined with the manner in which the preschool HAI variable operated (i.e., as a dichotomy between those who held exclusively benign attributions and those who reported any hostile attributions) raises the possibility that the preschool HAI measure assessed a construct distinct from the traditional formulation of hostile attribution of intent. Potential candidates for such an alternative account include general cognitive functioning, greater capacities for decontextualized thought, and social desirability in the testing situation. As well, the method of assessment of HAI may have advantaged the preschool measure over the Grade 1 measure.

A general cognitive account might suggest that the preschool HAI results are an artifact of general cognitive capacities, which are a known predictor of individual differences in children's externalizing behaviors. However, despite general cognitive functioning serving as a significant predictor of both the preschool and Grade 1 HAI measures, cognitive functioning did not account for the relationship between benign attribution tendencies and later social functioning. Nevertheless, it remains possible that some of the children who reported HAI in preschool failed to understand the questions or the concept of intentionality.

A more precise potential account, which ties together general cognitive functioning and our preschool HAI measure, might focus on children's capacity for cognitive decontextualization. Decontextualization is the capacity to "prise thought out of its primitive unconscious embeddedness in the immediacies of living" (Donaldson, 1978, p. 123; as cited in Stanovich, 1999, p. 170). For the majority of preschoolers, responses to the vignettes may reflect their own idiosyncratic history with similar scenarios. For example, children who have had a bad experience while playing ball may attribute hostile intentions for that question, but not for other questions. In other words, their judgments of intentions in hypothetical scenarios may reflect strongly contextualized thought based on specific memories or experiences, rather than any specific social cognitive rule or pattern of thinking. Other children, such as Pollyanna preschoolers, may be more advanced in their decontextualized thinking. For such children, these events may fit an interpretive rule or generic script as proposed by Crick \& Dodge (1994). In the case of our group, however, the script appeared to lead to benign attributions.

The interpretive rule that Pollyanna preschoolers might invoke, however, may not be a benign attribution rule at all. Rather, it is possible that it has more to do with social desirability in the testing situation. The affiliative social goal of promoting a positive interaction with the adult researcher might have been foremost in how they chose to respond. Such social desirability could account for the finding that Pollyanna preschoolers were seen as relatively well-behaved by mothers and teachers. The tendency to appear on one's "best behavior" might pervade the interactions of these children with adults.

It is important to remember that Pollyanna preschoolers did report hostile attributions-albeit fewer than the rest of the co- hort-in the first-grade assessment. If children are reporting socially desirable responses in preschool, research will need to address why they would not do so in first grade. Nevertheless, further research into children's prosocial goals with regard to the researcher might clarify how social desirability influences responses to the sorts of questions used in SIP research. Research combining quantitative analyses with qualitative interviewing methods might be able to assess how idiosyncratic child social experiences, decontextualization capacities, and social desirability might operate to influence responses to specific HAI vignettes.

Finally, it is possible that the difference in predictive strength of the preschool and first grade HAI measures may be due to the difference in assessment modes. In their meta-analysis of the relationship between HAI and aggressive behavior, Orobio de Castro et al. (2002) noted that HAI assessments that involved reading the scenario to the participants resulted in larger effects sizes than did assessments presented in pictures or videos. Orobio de Castro and his colleagues noted that reading the scenarios might maximize the children's imaginary sense of being directly involved.

The second major contribution of the present study stems from the investigation of antecedents of SIP. We found partial support for our hypothesis that maternal education, mediated by authoritarian attitudes, would be predictive of children's SIP. The hypothesis can only be considered partially supported because only maternal attitudes, and not maternal education, were related to HAI in Grade 1. However, this analysis controlled for preschool HAI, so the unique effect of maternal education on HAI in general may have been accounted for by inclusion of this earlier measure. The significant effect of authoritarian attitudes in predicting HAI in first grade, even following entry of preschool HAI, suggests an ongoing importance of parenting attitudes to the development of children's SIP. As children arrive at more complex understandings of the link between beliefs, intentions, and actions in the early schooling years, they may become more sensitive to the specific content of attitudes expressed by caregivers. Our assessment of authoritarian attitudes included the belief that children will be bad unless they are taught what is right. If this belief is communicated to children, they may begin to believe that people are fundamentally bad. This belief may foster HAI in children.

Further research examining the dyadic bases for this communication is an important next step in understanding the development of individual differences in social information processing. We recommend a developmentally sensitive approach that examines first the role of maternal education in preschool children's early capacities for decontextualization, followed by fine-tuning of children's interpretation of intention and motives influenced by parent attitudes during the early school years.

Finally, our hypotheses about the role of family income and parenting practices in predicting ARP were not supported, whereas the path from maternal education through authoritarian attitudes was found to be significant. Although ARP was not significant in the prediction of externalizing scores, this finding does reinforce the importance of maternal education and attitudes in the development of SIP in general.

There are several limitations that need to be considered regarding this study. First, it is possible that the ARP variable lacked construct validity. This represents a serious shortcoming of the assessment of social information processing for the NICHD- 
SECC. The original coding system implemented and ratified by the SECC research team (see Method) was not clearly ordinal, and some coding decisions seem problematic. Limiting the ARP variable to a count of clearly aggressive, retaliatory response plans was a pragmatic decision that may have limited the information that might have been available had an alternative coding system been employed originally.

In this study, the SIP variables explained little variance, accounting for only $1.8 \%$ of variance in teacher reports and $0.7 \%$ of variance in maternal reports. This raises questions about the utility of these measures as predictors of externalizing tendencies in community samples. Perhaps hostile attribution tendencies are held so commonly amongst young children that their predictive power is limited (cf., Schultz \& Shaw, 2003). Similarly, children may "talk the talk" of aggressive plans, without actually behaving aggressively, limiting predictive validity for this variable. The cultural context of the study is one in which aggressive social posturing is not rare; on the contrary, much popular media in America offers examples of aggressive solutions to causally ambiguous transgressions. In this context, the adoption of such discourse by young children is not surprising. Further research may seek to account for the influence of media exposure and other aspects of children's environments (e.g., neighborhood and school norms), as well as how families and children negotiate this wider social context.

Alternatively, the low predictive power of the SIP measures may reflect a deeper problem in the SIP research tradition. Most studies on children's SIP-including this one-rely on propositionalknowledge paradigms. Dodge and his colleagues have stated the need for measures that assess implicit processing (Burks, Laird, Dodge, Pettit, \& Bates, 1999). This remains a challenge, although promising avenues are being developed (e.g., Dadds et al., 2006), which may result in greater predictive power.

The correlational design used in the present study limits the conclusions that we can draw. As a nonexperimental study, statements about causality cannot be substantiated. Thus, despite use of the language of regression analyses (e.g., "predictors"), the current study taken on its own does not provide insight into risk factors in the development of children's externalizing tendencies or social information processing, but only risk markers.

The modest effect sizes for the social information processing variables in the current study limit the immediate implications of this research for policy makers. The correlational nature of the current study means that policy suggestions may be premature at best (McLennen \& Offord, 2003). Further research is required to replicate and explicate the Pollyanna preschooler finding before any specific policy implications are drawn. However, the modest effect sizes noted for social information processing variables may be instructive for policy makers, educators, and scientists who are designing universal preventive programs to reduce aggression in early childhood. Specifically, the importance of social information processing may be overstated for the majority of children. Social information processing styles, assessed through current research paradigms, may not accurately gauge children's likelihood of engaging in aggressive behaviors. It may be worthwhile to investigate the psychological and social conditions under which explicit SIP is more or less predictive of behavioral outcomes (Runions, 2006). For example, further research examining the intersection of emotion and SIP (e.g., Orobio de Castro, Slot, Bosch, Koops, \&
Veerman, 2003) may prove fruitful. Understanding the social and psychological moderators of the SIP-behavior link may be instructive in developing interventions to prevent conduct problems in the early years.

\section{References}

Achenbach, T. M., \& Edelbrock, C. (1983). Manual for the Child Behavior Checklist and Revised Child Behavior Profile. Burlington: University of Vermont.

Achenbach, T. M., \& Edelbrock, C. (1986). Manual for the Teacher's Report Form and Teacher Version of the Child Behavior Profile. Burlington: University of Vermont.

Andersson, H. W., Sommerfelt, K., Sonnander, K., \& Ahlsten, G. (1996). Maternal child rearing attitudes, IQ, and socioeconomic status as related to cognitive abilities of five-year-old children. Psychological Reports, 79, 3-12.

Astington, J. W. (2001). The paradox of intention: Assessing children's metarepresentational understanding. In B. F. Malle \& L. J. Moses (Eds.), Intentions and intentionality: Foundations of social cognition (pp. 85103). Cambridge, MA: MIT Press.

Baird, J. A., \& Moses, L. J. (2001). Do preschoolers appreciate that identical actions may be motivated by different intentions? Journal of Cognition \& Development, 2, 413-448.

Bickett, L. R., Milich, R., \& Brown, R. T. (1996). Attributional styles of aggressive boys and their mothers. Journal of Abnormal Child Psychology, 24, 457-472.

Blau, D. (1999). The effect of income on child development. Review of Economics and Statistics, 81, 261-276.

Bradley, R. H., \& Corwyn, R. F. (2002). Socioeconomic status and child development. Annual Review of Psychology, 53, 371-399.

Burks, V., Laird, R., Dodge, K., Pettit, G., \& Bates, J. (1999). Knowledge structures, social information processing, and children's aggressive behavior. Social Cognition, 8, 220-236.

Camras, L. A., Sachs-Alter, E., \& Ribordy, S. C. (1996). Emotion understanding in maltreated children: Recognition of facial expressions and integration with other emotion cues. In M. Lewis \& M. W. Sullivan (Eds.), Emotional development in atypical children (pp. 203-225). Hillsdale, NJ: Erlbaum.

Cassidy, J., Kirsh, S. J., Scolton, K. L., \& Parke, R. D. (1996). Attachment and representations of peer relationships. Developmental Psychology, 32, 892-904.

Chen, E., Langer, D. A., Raphaelson, Y. E., \& Matthews, K. A. (2004). Socioeconomic status and health in adolescents: The role of stress interpretations. Child Development, 75, 1039-1052.

Chen, E., \& Matthews, K. A. (2001). Cognitive appraisal biases: An approach to understanding the relation between socioeconomic status and cardiovascular reactivity in children. Annals of Behavioral Medicine, 23, 101-111.

Collins, L. M., Schafer, J. L., \& Kam, C. (2001). A comparison of inclusive and restrictive strategies in modern missing data procedures. Psychological Methods, 6, 330-351.

Costanzo, P. R., \& Dix, T. H. (1983). Beyond the information processed: Socialization in the development of attributional processes. In E. T. Higgins, D. N. Ruble, \& W. W. Hartup (Eds.), Social cognition and social development: A sociocultural perspective (pp. 63-81). Cambridge, England: Cambridge University Press.

Cowan, P. A., \& Cowan, C. P. (2002). Interventions as tests of family systems theories: Marital and family relationships in children's development and psychopathology. Development and Psychopathology, 14, 731-759.

Crick, N., \& Dodge, K. A. (1994). A review and reformulation of socialinformation-processing mechanisms of children's social adjustment. Psychological Bulletin, 115, 74-101. 
Crick, N., \& Dodge, K. A. (1996). Social information-processing mechanisms in reactive and proactive aggression. Child Development, 67, 993-1002.

Cutting, A. L., \& Dunn, J. (1999). Theory of mind, emotion understanding, language, and family background: Individual differences and interrelations. Child Development, 70, 853-865.

Dadds, M. R., Perry, Y., Hawes, D. J., Merz, S., Riddell, A. C., Haines, D. J., Solak, E., et al. (2006). Attention to the eyes and fear-recognition deficits in child psychopathy. British Journal of Psychiatry, 189, 280281

Darling, N., \& Steinberg, L. (1993). Parenting style as context: An integrative model. Psychological Bulletin, 113, 487-496.

Dearing, E., McCartney, K., \& Taylor, B. A. (2001). Change in family income-to-needs matters more for children with less. Child Development, 72, 1779-1793.

Dishion, T. J., French, D. C., \& Patterson, G. R. (1995). The development and ecology of antisocial behavior. In D. Cichetti \& D. J. Cohen (Eds.), Developmental psychopathology: Vol. 2. Risk, disorder, and adaptation (pp. 421-471). New York: Wiley.

Dodge, K. A. (1980). Social cognition and children's aggressive behavior. Child Development, 51, 162-170.

Dodge, K. A., \& Coie, J. D. (1987). Social-information-processing factors in reactive and proactive aggression in children's peer groups. Journal of Personality \& Social Psychology, 53, 1146-1158.

Dodge, K. A., Lansford, J. E., Burks, V. S., Bates, J. E., Pettit, G. S., Fontaine, R., et al. (2003). Peer rejection and social informationprocessing factors in the development of aggressive behavior problems in children. Child Development, 74, 374-393.

Dodge, K. A., Pettit, G. S., Bates, J. E., \& Valente, E. (1995). Social information-processing patterns partially mediate the effect of early physical abuse on later conduct problems. Journal of Abnormal Psychology, 104, 632-643.

Dodge, K. A., Pettit, G. S., McClaskey, C. L., \& Brown, M. M. (1986). Social competence in children. Monographs of the Society for Research in Child Development, 51(2, Serial No. 213).

Dodge, K. A., Price, J. M., Bachorowski, J. A., \& Newman, J. P. (1990). Hostile attributional biases in severely aggressive adolescents. Journal of Abnormal Psychology, 99, 385-392.

Downey, G., \& Coyne, J. C. (1990). Children of depressed parents: An integrative review. Psychological Bulletin, 108, 50-76.

Downey, G., \& Walker, E. (1989). Social cognition and adjustment in children at risk for psychopathology. Developmental Psychology, 25, 835-845.

Feshbach, L. E. (1989). Aggression-conduct problems, attention-deficits hyperactivity, play, and social cognition in four-year-old boys. Dissertation Abstracts International, 50(12), 5878.

Gomez, R., Gomez, A., DeMello, L., \& Tallent, R. (2001). Perceived maternal control and support: Effects on hostile biased social information processing and aggression among clinic-referred children with high aggression. Journal of Child Psychology, Psychiatry and Allied Disciplines, 42, 513-522.

Gomez, R., \& Hazeldine, P. (1996). Social information processing in mild mentally retarded children. Research in Developmental Disabilities, 17, 217-227.

Goodman, J. S., \& Blum, T. C. (1996). Assessing the non-random sampling effects of subject attrition in longitudinal research. Journal of Management, 22, 627-652.

Guerra, N. G., \& Slaby, R. G. (1989). Evaluative factors in social problem solving by aggressive boys. Journal of Abnormal Child Psychology, 17, 277-289.

Hart, C. H., Ladd, G. W., \& Burleson, B. (1990). Children's expectations of the outcomes of social strategies: Relations with sociometric status and maternal disciplinary styles. Child Development, 61, 127-137.

Jacobusse, G. (2005). WinMICE User's Manual for WinMICE prototype
(Version 0.1). Leiden, The Netherlands: Netherlands Organization for Applied Scientific Research (TNO). Retrieved June 2, 2006 from http:// web.inter.nl.net/users/S.van.Buuren $/ \mathrm{mi} / \mathrm{hmtl} / \mathrm{mice} . \mathrm{htm}$

Katsurada, E., \& Sugawara, A. I. (1998). The relationship between hostile attribution bias and aggressive behavior in preschoolers. Early Childhood Research Quarterly, 13, 623-636.

MacBrayer, E. K., Milich, R., \& Hundley, M. (2003). Attributional biases in aggressive children and their mothers. Journal of Abnormal Psychology, 112, 698-708.

MacKinnon, D. P., \& Dwyer, J. H. (1993). Estimating mediated effects in prevention studies. Evaluation Review, 17, 144-158.

Matthys, W., Cuperus, J. M., \& van Engeland, H. (1999). Deficient social problem-solving in boys with ODD/CD, with ADHD, and with both disorders. Journal of the American Academy of Child and Adolescent Psychiatry, 38, 311-321.

McLennen, J., \& Offord, D. R. (2003). Clinical and policy implications for prevention [letter to the editor]. Journal of the American Academy of Child and Adolescent Psychiatry, 42, 513-514.

NICHD Early Child Care Research Network. (1999a). Child care and mother-child interaction in the first 3 years of life. Developmental Psychology, 35, 1399-1413.

NICHD Early Child Care Research Network. (1999b). Chronicity of maternal depressive symptoms, maternal sensitivity, and child functioning at 36 months. Developmental Psychology, 35, 1297-1310.

NICHD Early Child Care Research Network. (2005). Predicting individual differences in attention, memory, and planning in first graders from experiences at home, child care, and school. Developmental Psychology, 41, 99-114.

Orobio de Castro, B., Slot, N. W., Bosch, J. D., Koops, W., \& Veerman, J. W. (2003). Negative feelings exacerbate hostile attributions of intent in highly aggressive boys. Journal of Clinical Child \& Adolescent Psychology, 32, 56-65.

Orobio de Castro, B. O., Veerman, J. W., Koops, W., Bosch, J. D., \& Monshouwer, H. J. (2002). Hostile attributions of intent and aggressive behavior: A meta-analysis. Child Development, 73, 916-934.

Pears, K. C., \& Moses, L. J. (2003). Demographics, parenting, and theory of mind in preschool children. Social Development, 12, 1-19.

Pettit, G. S., Dodge, K. A., \& Brown, M. M. (1988). Early family experience, social problem solving patterns, and children's social competence. Child Development, 59, 107-120.

Preacher, K. J., \& Leonardelli, G. J. (2001). Calculation for the Sobel test: An interactive calculation tool for mediation tests. Retrieved October 6, 2006 from http://www.unc.edu/ preacher/sobel/sobel.htm

Rubin, D. B. (1976). Inference and missing data. Biometrika, 63, 581-592.

Rubin, K. H., Burgess, K. B., Dwyer, K. M., \& Hastings, P. D. (2003). Predicting preschoolers' externalizing behaviors from toddler temperament, conflict, and maternal negativity. Developmental Psychology, 39, $164-176$.

Rubin, K. H., Hastings, P., Chen, X., Stewart, S., \& McNichol, K. (1998). Intrapersonal and maternal correlates of aggression, conflict, and externalizing problems in toddlers. Child Development, 69, 1614-1629.

Runions, K. C. (2006, July). Temperament as a moderator of social information processing in early childhood social competence. In K. Runions \& B. Orobio de Castro (Co-chairs), The validity of social information processing: Can incorporating emotion help? Symposium conducted at the 19th biennial meeting of the International Society for the Study of Behavioral Development, Melbourne, Australia.

Schafer, J. L. (2000). NORM for Windows 95/98/NT: Multiple imputation of incomplete multivariate data under a normal model (Version 2.03) [Computer software]. Retrieved March 3, 2006 from http://www.stat .psu.edu/ jls/misoftwa.html\#win

Schafer, J. L., \& Olsen, M. (1998). Multiple imputation for multivariate missing-data problems: A data analyst's perspective. Multivariate Behavioral Research, 33, 545-571. 
Schultz, D., \& Shaw, D. S. (2003). Boys' maladaptive social information processing, family emotional climate, and pathways to early conduct problems. Social Development, 12, 440-460.

Shaw, D. S., Owens, E. B., Giovannelli, M. S., \& Winslow, E. B. (2001). Infant and toddler pathways leading to early externalizing disorders. Journal of the American Academy of Child and Adolescent Psychiatry, 40, 36-43.

Shultz, T. R., Wells, D., \& Sarda, M. (1980). Development of the ability to distinguish intended actions from mistakes, reflexes, and passive movements. British Journal of Social and Clinical Psychology, 19, 301-310.

Stanovich, K. E. (1999). Who is rational? Studies in individual differences in reasoning. Mahwah, $\mathrm{NJ}$ : Erlbaum.

van Buuren, S., \& Oudshoorn, C. G. M. (2000). Multivariate Imputation by Chained Equations: MICE User's Manual (Version 1.0). TNO Report PG/VGZ/00.038. Leiden, The Netherlands: The Netherlands Organization for Applied Scientific Research (TNO) Institute Prevention and Health. Retrieved June 2, 2006 from http://web.inter.nl.net/users/ S.van.Buuren $/ \mathrm{mi} / \mathrm{hmt} / \mathrm{mice} \cdot \mathrm{htm}$

von Hippel, P. T. (2005). How many imputations are needed? A comment on Hershberger and Fisher (2003). Structural Equation Modeling, 12, 334-335.

von Hippel, P. T. (n.d.). Spreadsheet for multiple imputation inference. Retrieved September 24, 2006, from http://www.sociology.ohiostate.edu/people/ptv/faq/MI_spreadsheet/MI_spreadsheet.htm
Wahler, R. G., \& Dumas, J. E. (1989). Attentional problems in dysfunctional mother-child interactions: An interbehavioral model. Psychological Bulletin, 195, 116-130.

Webster-Stratton, C., \& Lindsay, D. W. (1999). Social competence and conduct problems in young children: Issues in assessment. Journal of Clinical Child Psychology, 28, 25-43.

Weiss, B., Dodge, K. A., Bates, G. E., \& Pettit, G. S. (1992). Some consequences of early harsh discipline: Child aggression and a maladaptive social information processing style. Child Development, 63, 13211335.

Wellman, H. M., \& Wooley, J. D. (1990). From simple desires to ordinary beliefs: The early development of everyday psychology. Cognition, 35, 245-275.

Zelli, A., Dodge, K. A., Lochman, J. E., Laird, R. D., \& Conduct Problems Prevention Research Group. (1999). The distinction between beliefs legitimizing aggression and deviant processing of social cues: Testing measurement validity and the hypothesis that biased processing mediates the effects of beliefs on aggression. Journal of Personality and Social Psychology, 77, 150-166.

Received March 18, 2005 Revision received October 18, 2006 Accepted November 6, 2006

\section{Low Publication Prices for APA Members and Affiliates}

Keeping you up-to-date. All APA Fellows, Members, Associates, and Student Affiliates receive-as part of their annual dues-subscriptions to the American Psychologist and APA Monitor. High School Teacher and International Affiliates receive subscriptions to the APA Monitor, and they may subscribe to the American Psychologist at a significantly reduced rate. In addition, all Members and Student Affiliates are eligible for savings of up to $60 \%$ (plus a journal credit) on all other APA journals, as well as significant discounts on subscriptions from cooperating societies and publishers (e.g., the American Association for Counseling and Development, Academic Press, and Human Sciences Press).

Essential resources. APA members and affiliates receive special rates for purchases of APA books, including the Publication Manual of the American Psychological Association, and on dozens of new topical books each year.

Other benefits of membership. Membership in APA also provides eligibility for competitive insurance plans, continuing education programs, reduced APA convention fees, and specialty divisions.

More information. Write to American Psychological Association, Membership Services, 750 First Street, NE, Washington, DC 20002-4242. 